\title{
Vasoactive intestinal peptide, whose receptor-mediated signalling may be defective in alopecia areata, provides protection from hair follicle immune privilege collapse
} DOI:

10.1111/bjd.14645

\section{Document Version \\ Accepted author manuscript}

Link to publication record in Manchester Research Explorer

Citation for published version (APA):

Bertolini, M., Pretzlaff, M., Sulk, M., Bähr, M., Gherardini, J., Uchida, Y., Reibelt, M., Kinori, M., Rossi, A., Bíró, T., \& Paus, R. (2016). Vasoactive intestinal peptide, whose receptor-mediated signalling may be defective in alopecia areata, provides protection from hair follicle immune privilege collapse. British Journal of Dermatology, 175(3), 531-541. https://doi.org/10.1111/bjd.14645

\section{Published in:}

British Journal of Dermatology

\section{Citing this paper}

Please note that where the full-text provided on Manchester Research Explorer is the Author Accepted Manuscript or Proof version this may differ from the final Published version. If citing, it is advised that you check and use the publisher's definitive version.

\section{General rights}

Copyright and moral rights for the publications made accessible in the Research Explorer are retained by the authors and/or other copyright owners and it is a condition of accessing publications that users recognise and abide by the legal requirements associated with these rights.

\section{Takedown policy}

If you believe that this document breaches copyright please refer to the University of Manchester's Takedown Procedures [http://man.ac.uk/04Y6Bo] or contact uml.scholarlycommunications@manchester.ac.uk providing relevant details, so we can investigate your claim.

\section{OPEN ACCESS}


Received Date : 20-Apr-2015

Revised Date : 26-Feb-2016

Accepted Date : 21-Mar-2016

Article type : Original Article

\section{VIP, whose receptor-mediated signalling may be defective in alopecia areata, provides protection from hair follicle immune privilege collapse}

Running head: VIP and alopecia areata

M. Bertolini, ${ }^{1 \&}$ M. Pretzlaff, ${ }^{2 \#}$ M. Sulk, ${ }^{1 \#}$ M. Bähr, ${ }^{2}$ J. Gherardini, ${ }^{1}$ Y. Uchida, ${ }^{1,3}$ M. Reibelt, ${ }^{2}$ M. Kinori, ${ }^{4}$

A. Rossi, ${ }^{5}$ T. Bíró ${ }^{6}$ and R. Paus ${ }^{1,7}$

1 Department of Dermatology, University of Münster, Münster, Germany

2 Department of Dermatology, University of Lübeck, Lübeck, Germany

3 Department of Dermatology, Kagoshima University Graduate School of Medical and Dental Sciences, Kagoshima, Japan

4 Department of Ophthalmology, Sheba Medical Center, Tel Hashomer, Israel

5 Department of Internal Medicine and Medical Specialties, University "La Sapienza", Rome, Italy

6 DE-MTA "Lendület" Cellular Physiology Research Group, Departments of Immunology and Physiology, Faculty of Medicine, University of Debrecen, Debrecen, Hungary

This article has been accepted for publication and undergone full peer review but has not been through the copyediting, typesetting, pagination and proofreading process, which may lead to differences between this version and the Version of Record. Please cite this article as doi: $10.1111 / \mathrm{bjd} .14645$ 
7 The Centre for Dermatology Research, Institute for Inflammation and Repair, University of Manchester, Manchester, UK

\# Equivalent contribution

\& Corresponding author: Marta Bertolini, Department of Dermatology, University of Münster, von-EsmarchStr. 5848149 Münster, +49251-83-56523, marta.bertolini@ ukmuenster.de

Funding sources: This study was partially supported by a grant from the DFG to RP (GRK1727/1, Modulation of Autoimmunity MD fellowship for MP).

Conflict of interest disclosures: None

1) What's already known about this topic?

- Alopecia areata (AA) pathogenesis involves the collapse of hair follicle (HF)-immune privilege (IP).

- Vasoactive intestinal peptide (VIP) is an immunoinhibitory neuropeptide released by perifollicular nerve fibers fundamental for immune homeostasis.

2) What does this study add?

- VIP receptors are expressed in human HFs

- AA hair bulbs present defects in VIP receptor expression but not in $\mathrm{VIP}^{+}$nerve fibre density

- VIP administration prevents and partially restores experimentally induced HF-IP collapse

This article is protected by copyright. All rights reserved. 


\section{Summary:}

Background: Alopecia areata (AA) is an autoimmune disorder whose pathogenesis involves the collapse of the relative immune privilege (IP) of the hair follicle (HF). Given that vasoactive intestinal peptide (VIP) is an immunoinhibitory neuropeptide released by perifollicular sensory nerve fibres, which plays a role in IP maintenance, it may modulate human HF-IP and thus therapeutically relevant for AA. Objectives: Do human HFs express VIP receptors, and does their stimulation protect from or restore experimentally induced HF-IP collapse? Is VIP signalling defective in AA HFs? Methods: First, VIP and VIP receptors (VPAC1, VPAC2) expression in human scalp HFs and AA skin was assessed. In HF organ culture, we then explored whether VIP treatment can restore and/or protect from interferon $\gamma$-induced HF-IP collapse, assessing the expression of the key IP markers by quantitative (immuno-)histomorphometry. Results: Here, we provide the first evidence that VIP receptors are expressed in the epithelium of healthy human HFs at the gene and protein level and that VIP receptor protein expression, but not VIP ${ }^{+}$nerve fibres, is significantly down-regulated in lesional hair bulbs of AA patients, suggesting defects in VIP receptormediated signalling. Moreover, we show that VIP protects the HF from experimentally induced IP collapse in vitro, but does not fully restore it once collapsed. Conclusions: These pilot data suggest that insufficient VIP receptor-mediated signalling may contribute to impairing HF-IP in AA patients and that VIP is a promising candidate "HF-IP guardian" that may be therapeutically exploited to inhibit the progression of AA lesions.

\section{Introduction}

Collapse of the relative immune privilege (IP) of the hair follicle (HF), namely by interferon (IFN) $\gamma$, is recognized as a key element in the pathogenesis of the autoimmune hair loss disorder, alopecia areata (AA) ${ }^{1,2}$ Therefore, more efficient AA therapeutics need to be to identified that can prevent and, ideally, restore the IFN $\gamma$-induced IP collapse of human scalp HFs. ${ }^{2,3}$

This article is protected by copyright. All rights reserved. 
Using a previous established human HF organ culture assay for inducing IP collapse by IFN $\gamma$, we had found that transforming-growth factor $\beta 1$ (TGF $\beta 1$ ), insulin growth factor-1, FK506, and the immunoinhibitory neuropeptide $\alpha$-melanocyte-stimulating hormone ( $\alpha-\mathrm{MSH})$, can both prevent and restore HF-IP collapse; ${ }^{4}$ this had been assessed primarily by the down-regulation of ectopic and excessive expression of MHC class I and MHC class II by normally MHC class I- and II-negative compartments of the HF epithelium..$^{3-6}$ Instead, calcitonin gene related peptide (CGRP), another important immunoinhibitory neuropeptide, could only prevent and partially restore IP collapse in this assay. ${ }^{7}$ In contrast, substance P, a key neuropeptide involved in stress-induced neurogenic skin inflammation, strongly promotes HF-IP collapse in man and mice.,

Therefore, we asked whether another key immunoinhibitory neuropeptide, vasoactive intestinal peptide $(\mathrm{VIP})^{10-13}$ unfolds similar IP-protective properties as a-MSH and CGRP. ${ }^{4,7}$ This question was encouraged by the observation that VIP is known to operate as one of the key guardians of ocular IP, ${ }^{14-18}$ and that VIP is prominently stored and released by cutaneous sensory nerve fibres, also in human skin and around human HFs. ${ }^{19-24}$ Therefore, after reinvestigating the expression of VIP in perifollicular nerve fibres, we have explored if healthy human scalp HFs express VIP receptors (VPAC1, VPAC2), and compared the expression of VIP and its receptors with lesional HFs from patients with AA. In HF organ culture, we then explored whether VIP treatment can restore and/or protect from IFN $\gamma$-induced HF-IP collapse, assessing the expression of the key IP markers, MHC class I, MHC class II, and $\beta 2$-microglobulin, by quantitative (immuno-)histomorphometry. ${ }^{4,6,7}$

\section{Materials and Methods}

\section{Human samples}

For investigating VIP receptor expression, human lesional skin biopsies were obtained from 3 AA patients in acute or subacute disease phase after written patient consent and ethic committee approval from the University "La Sapienza" of Rome (n. 2973, 28-11-13). Additional lesional AA skin was obtained from archival paraffin blocks of 7 AA patients in acute or subacute disease phase and after ethics committee

This article is protected by copyright. All rights reserved. 
approvals (University of Luebeck, n. 13-007, 13-03-13 and University of Muenster, n. 2014-041-b-N, 2201-14). As control, 10 clinically "healthy" frontotemporal human skin scalp specimens were obtained from women without a sign of AA undergoing cosmetic facelift surgery after ethics committee approvals (University of Luebeck, n. 06-109, 18-07-06 and University of Muenster, n. 2014-041-b-N, 22-01-14) and written patient consent.

For the analysis of $\mathrm{VIP}^{+}$nerve fibers, human skin biopsies were obtained from 3 healthy donors and $2 \mathrm{AA}$ patients in acute and chronic disease phase after written patient consent and ethics committee approval from the University of Muenster (n. 2015-602-f-S, 3-12-15).

As positive control tissues for immunohistology, anonymised human gastrointestinal tract tissue was obtained from the Dept. of Pathology, University of Luebeck, with ethics approval (University of Luebeck, n. 06-109, 20-01-2009 and University of Muenster, n. 2014-041-b-N, 22-01-14). All experiments were performed according to Helsinki guidelines.

\section{HF organ culture}

Normal human anagen VI scalp HFs were microdissected from 7 female healthy individuals having facelift surgery after written patient consent and ethics committee approval (University of Luebeck, n. 06-109, 18-07-06 and University of Muenster, n. 2014-041-b-N, 22-01-14) and organ-cultured as described. ${ }^{4,6,7,25}$ After 24 hrs of incubation in supplemented William's E medium, the HFs were organized in two different HF organ culture set-ups:

In the "protection assay" ( $\operatorname{PrA}$ ) design, ${ }^{6,7} \mathrm{HFs}$ were first treated with $10^{-7}, 10^{-9}$ or $10^{-12} \mathrm{M}$ VIP (Bachem, Bubendorf, Switzerland) and $5 \mu \mathrm{M}$ phosporamidon (Sigma Aldrich, Taufkirchen, Germany) for 2 days, followed by 5 days of incubation after $75 \mathrm{IU} / \mathrm{mL}$ IFN $\gamma$ (Peprotech, Rocky Hill, NJ, USA) were added. ${ }^{4}$

Instead, in the "restoration assay" (ReA) design, ${ }^{4,6,7} \mathrm{HFs}$ were first treated with $75 \mathrm{IU} / \mathrm{mL} \mathrm{IFN} \gamma$ for 5 days to induce HF-IP collapse. ${ }^{4}$ On day $3,10^{-7}, 10^{-9}$ or $10^{-12} \mathrm{M}$ VIP and $5 \mu \mathrm{M}$ phosporamidon were added.

This article is protected by copyright. All rights reserved. 
For control purposes, HFs were exclusively cultured with only $10^{-7} \mathrm{M}$ VIP, IFN $\gamma$, phosphoramidon or with culture medium (our vehicle) in the same period. The medium was exchanged regularly every other day.

After $5(\operatorname{ReA})$ or 7 days $(\operatorname{PrA})$ of organ culture, HFs were frozen in liquid nitrogen, stored at $-80^{\circ} \mathrm{C}$ and 6 $\mu \mathrm{m}$ cryosections were prepared.

When no significant differences were seen between the $10^{-7} \mathrm{M}$ VIP, and phosphoramidon-treated groups compared to the vehicle groups, the results of these groups were not incorporated in the graphs.

For testing if INF $\gamma$ treatment modulates VPACs expression, after one night of incubation, microdissected HFs were cultured for 4 days, treated everyday with $75 I \mathrm{U} / \mathrm{ml}$ of INF $\gamma$, fixed in $4 \%$ formalin and embedded in paraffin.

\section{Immunohistology}

For detecting nerve fibres, the tissue was fixed in 4\%PFA for 6hrs, cryoprotected in $15 \%$ sucrose for 24 hrs and mounted in OCT. A rabbit anti-human VIP antibody (Abcam, ab8556, 1:50) and a rabbit antihuman pgp9.5 antibody (UltraClone, RA95101, 1:800) were used in $25 \mu \mathrm{m}$ thick sections for the single immunofluorescence for VIP and double immunofluorescence for PGP9. $5^{26}$ and VIP.

Indirect immunofluorescence staining for VPAC1 was performed on paraffin sections using FITC-tyramide amplification system and a rabbit anti-human VPAC1 antibody (Novus Biologicals, NBP1-89640, 1:200) as primary antibody. ${ }^{4,6}$

Immunohistochemistry for VPAC2 was performed on paraffin sections using horseradish peroxidasebased avidin-biotin complex, rabbit anti human VPAC2 as primary antibody (Abcam, ab28624, 1:1000) and $3,3^{\prime}$-diaminobenzidine as substrate. ${ }^{6,27,28}$

Immunofluorescence microscopy for MHC class I and $\beta 2$ microglobulin were performed using the monoclonal mouse anti-human MHC class la antibody (DAKO, W6/32, 1:50) and monoclonal mouse antihuman $\beta 2$ microglobulin antibody (BD pharmigen, TÜ99, 1:100) following previously published

This article is protected by copyright. All rights reserved. 
protocols. ${ }^{6,7,27}$ MHC class II immunohistochemistry was executed using the avidin and biotin based method $^{6,7,27}$ and the (monoclonal) mouse anti-human MHC class II antibody (DAKO, CR3/43, 1:50). Double immunofluorescence microscopy for CD68/MHC class II was performed using the TSA method for CD68 and a mouse anti-human CD68 as primary antibody (DAKO, EBM11, 1:2000), followed by indirect immunofluorescence for MHC class II. ${ }^{27}$

\section{Quantitative immunohistomorphometry}

Images of immunostained HF sections were taken at an original magnification of 200x with a KeyenceBiozero 8100 and 9000 microscopes (Keyence Corporation, Osaka, Japan). VPACs, MHC class I and ß2microglobulin IR were analysed within defined reference areas (Figs 4a and 5j) using Image $\mathrm{J}$ (Wayne Rasband, $\mathrm{NIH}$ ). In the HF mesenchyme, MHC class $\mathrm{II}^{+}$cells, and $\mathrm{MHC}$ class $\mathrm{II}^{+} \mathrm{CD} 8^{+}$cells were counted exclusively in the peribulbar CTS (Fig. 5o). ${ }^{6,7}$

\section{Quantitative real-time polymerase chain reaction (RT-qPCR)}

In order to detect the mRNA expression of VPAC1, VPAC2 and VIP in the HF epithelium, RT-qPCR experiments were performed on dispase treated microdissected HFs obtained from 3 different "clinically" healthy donors after written patient consent and ethics committee approval (University of Luebeck, n. 06109, 18-07-06 and University of Muenster, n. 2014-041-b-N, 22-01-14), on a Stratagene Mx3005P QPCR System (Agilent Technologies) using the 5' nuclease assay. RNA was isolated using TRIzol (LifeTechnologies) and $1 \mu \mathrm{g}$ was reverse-transcribed into cDNA (Life Technologies). PCR amplification was performed by using the TaqMan technology (assay IDs: Hs00270351_m1 for human VPAC1, Hs 00173643_m1 for human VPAC2, and Hs00175021_m1 for human VIP) (Applied Biosystems). As internal control, transcript of $\beta$-actin (ACTB) was determined (assay ID: Hs99999903_m1). The amount of the transcripts was normalized to those of the housekeeping gene using the $\triangle \triangle C T$ method.

This article is protected by copyright. All rights reserved. 


\section{Results}

VIP is present only in perifollicular nerve fibres, but not in the epithelium of human scalp HFs Initially, we reinvestigated whether human scalp skin HFs express VIP at the gene and protein level. RTqPCR analysis revealed that VIP transcript was almost undetectable in mRNA extracted from microdissected human HF epithelium (Fig. 1). Moreover, the very low level of VIP transcripts detected (Fig. 1) did not correspond to the presence of intrafollicular VIP IR, which was clearly restricted to perifollicular nerve fibres (Fig. 2a-f). This suggests that the minimal transcriptional activity for VIP is associated with Merkel cells, which are richly distributed throughout the ORS of human scalp $\mathrm{HFs}^{29,30}$ and are capable to synthesize VIP. ${ }^{21,31,32}$

\section{VIP receptors (VPAC1 and VPAC2) are expressed by the HF epithelium}

In contrast, VPAC1 is transcribed in the epithelium of human scalp anagen VI HFs (Fig. 1). In line with previous published results obtained by using in situ hybridization technique in human skin, ${ }^{33,34}$ we confirm that also VPAC2 mRNA is expressed in the epithelium of human scalp anagen VI HFs, with substantial interindividual expression differences (data not shown). Human skin paraffin sections stained for VPACs revealed that VPAC1 and VPAC2 are also strongly expressed on the protein level (Fig. 3a-k), most prominently in the epithelium of the anagen hair bulb (Fig. 3e,j). While VPAC1 IR in the bulge and lower ORS was relatively faint (Fig. 3c,d), VPAC2 IR was strong in basal layer ORS keratinocytes in the bulge (Fig. 3h), yet almost absent in the lower ORS (Fig. 3i). This may correspond to the peculiarly restricted VIP receptor-like IR that we had previously observed in the bulge region of murine HFs, but only during anagen $\mathrm{V}^{35}$ In the HF CTS, few immune cells were also positive for VPAC1 and/or VPAC2 (Fig. 3e,h-j). Moreover, cell morphology suggests that these represent immunocytes such as mast cells, macrophages and T-cells, in line with previous reports in the neuroimmunology literature ${ }^{10,13,17,36,37}$, and probably endothelial cells. ${ }^{38}$

This article is protected by copyright. All rights reserved. 


\section{VPAC1 and VPAC2 but not VIP protein expression is abnormal in lesional HFs from AA patients}

Next, we assessed whether VIP and VPACs expression is abnormal in AA patients. As shown in Fig. 4a-f, both VPAC1 and VPAC2 protein expression was significantly down-regulated in the anagen hair bulbs of lesional HFs from AA patients compared to scalp HFs from healthy controls. While we do not know whether this is a constitutive defect or secondary to AA-associated inflammation, this finding suggests that lesional scalp HFs are less responsive to VIP stimulation in AA. In contrast, we did not find any major differences in $\mathrm{VIP}^{+}$nerve fibres density expression around anagen hair bulbs in AA lesional skin compared to the skin of healthy controls (Fig. $4 \mathrm{~g}-\mathrm{j})$.

\section{VIP protects from INF $\gamma$-induced HF-IP collapse}

These observations encouraged us to study, next, functionally in microdissected, organ-cultured human anagen VI HFs whether and how VIP impacts on experimentally induced HF-IP collapse by IFN $\gamma$ treatment. ${ }^{4,6,7,25}$ First, HFs were treated with VIP $\left(10^{-7}, 10^{-9}, 10^{-12} \mathrm{M}\right)$ before IFN $\gamma$ administration ("protection assay" [PrA]); subsequently, key IP markers ${ }^{3}$ were assessed by quantitative (immuno-)histomorphometry as previously described. ${ }^{6,7}$

This showed that VIP significantly inhibited and essentially prevented the IFN $\gamma$-induced ectopic and excessive up-regulation of MHC class I protein in the bulb HM, proximal ORS and CTS, when VIP was administered before IFN $\gamma$ ("PrA" design); however, this was only seen with one VIP concentration (VIP10" $\left.{ }^{9} \mathrm{M}\right)$ (Fig. 5a-d).

In contrast, VIP was not able to suppress the IFN $\gamma$-stimulated overexpression of $\beta 2$-microglobulin protein, which is important for MHC class I conformation, stability, and function ${ }^{39-41}$ (Fig. 5e) and is normally absent or very low in the anagen hair bulb epithelium..$^{3,5,6}$

In addition, prophylactic VIP administration $\left(10^{-9}\right.$ and $\left.10^{-12} \mathrm{M}\right)$ also significantly prevented the IFN $\gamma$-induced up-regulation of MHC class II expression in the CTS (Fig. 5f-i) but not in ORS and HM (Supplementary Figs S1a and S2a-c).

This article is protected by copyright. All rights reserved. 


\section{VIP does not fully restore an already collapsed HF-IP}

We then tested whether administering VIP after the induction of HF-IP collapse was capable of restoring it ("restoration assay" [ReA]). This revealed that VIP failed to re-establish the low expression level of MHC class I (Fig. 5j-m) and $\beta 2$-microglobulin (Fig. 5n) that is characteristic for an intact HF-IP., ${ }^{3,5,6}$ Importantly, however, VIP significantly down-regulated MHC class II protein expression in the CTS (Fig. 5o-r) and thus partially restored the MHC class II-dependent component of HF-IP. ${ }^{3}$ Yet, no effect of VIP was seen on the IFN $\gamma$-induced MHC class II overexpression in the ORS and HM epithelium in the "ReA" design (Supplementary Figs S1b and S2d-f).

That IFN $\gamma$-induced MHC class II expression was down-regulated by VIP only in the HF mesenchyme raised the question how VIP affected perifollicular macrophages given that most MHC class $\mathrm{II}^{+}$cells in the CTS are macrophages. ${ }^{5,42}$ We expected these CD $68^{+}$CTS cells to be most affected by the administration of VIP after IFN $\gamma$-induced HF-IP collapse, however, this was not the case (Supplementary Figs S2a-f and S3a-d). IFN $\gamma$ up-regulates MHC class II expression also on other cells of the CTS distinct from macrophages and the treatment with VIP tended to counteract this phenomenon (Supplementary Figs S2a-f and S3c,d). The most likely candidates are mast cells and dermal endothelial cells, since both cell populations have been reported to posses VPACs ${ }^{38}$ and express MHC class II upon certain activation, in particular after IFN $\gamma$ stimulation. ${ }^{43-45}$

As an attempt to search for evidence of VIP failure to restore MHC class I expression in the bulb and MHC class II expression in the HF epithelium, we have checked if VPACs expression is down-regulated in microdissected HFs after INF $\gamma$ treatment. Surprisingly, we have found that VPACs expression in the HF proximal ORS of INF $\gamma$ treated HFs did not change compared vehicle HFs (Supplementary Fig. 4a-f).

This article is protected by copyright. All rights reserved. 


\section{Discussion}

Here, we provide the first evidence that VIP receptors (VPAC1, VPAC2) are expressed in the epithelium of human healthy HFs at the gene and protein level (Figs 1-3) and that VPAC protein expression is significantly down-regulated in lesional HFs of AA patients (Fig. 4a-f), suggesting defects in VIP receptormediated signalling. Most importantly, VIP is capable of awarding relative protection from the induction of HF-IP collapse by IFN $\gamma$, the major pathogenesis-driving cytokine in $A A,{ }^{1,2}$ but cannot fully restore an already collapsed HF-IP.

These pilot data cast new light on the potential role of this major immunoinhibitory neuropeptide in human HF biology and pathology. Our observations raise the possibility that, under physiological conditions in vivo, VIP receptor-expressing HFs are stimulated by the release of VIP from perifollicular sensory nerve fibres and that helps to maintain HF-IP during anagen stage and to protect it from collapse. This theory is well in line with the concept that VIP is a pleiotropic immunoihibitory peptide fundamental for immune homeostasis and IP maintenance, namely in the eye. ${ }^{10,11,13,16-18,36,46}$ Besides further underscoring the similarities between human eye and HF-IP, ${ }^{14}$ conceptually, our study identifies VIP as an important new "HF-IP guardian" neuropeptide, whose immunoprotective effect can overcome even the most important inducer of HF-IP collapse, IFN $\gamma$ (Fig. 5a-r). Thus, while not being as effective as $\alpha$-MSH in its "HF-IP guardian" properties, which can also restore a collapsed HF-IP, ${ }^{3,4}$ VIP is able to prevent the IFN $\gamma$-induced HF-IP collapse, which most likely mimics a critical early event in AA pathobiology. ${ }^{2}$

Interestingly, VIP treatment is not only effective on restoring the HF-IP collapse in the epithelium (MHC class I down-regulation) but exerts a protective role also on the HF CTS (Fig. 5). This may be explained by the fact that the binding of VIP to its receptors, in particular VPAC1, is known to exert an immunoinhibitory effect on immune cells, namely by decreasing the release of pro-inflammatory cytokines and increasing the release of immunoinhibitory mediators. ${ }^{10,13,17,36}$ As a consequence, the proinflammatory environment caused by INF $\gamma$ treatment may be attenuated by the release of immunoinhibitory cytokines from immune cells localized in the CTS. Moreover, in the restoration assay, VIP treatment may downregulate the INF $\gamma$-induced upregulation of $\mathrm{MHCI}$ on endothelial cells. In addition,

This article is protected by copyright. All rights reserved. 
the restoring of the HF-IP in the anagen hair bulb after VIP treatment re-establishes the release of immunosuppressive "IP guardians" (e.g. TGFbeta1, IL-10, TGFbeta2), ${ }^{6,27}$ by the HF epithelium. This may further decrease CTS inflammation.

Importantly, our data suggest that AA patients display normal VIP IR (Fig. 4g-j) but a decreased intrafollicular VIP receptor expression (Fig. 4a-f), which may be even further decreased in patients characterized by late AA. Interestingly, AA patients have increased expression of neutral endopeptidase, ${ }^{47}$ a key VIP-degrading enzyme. ${ }^{48}$ If additional analyses confirm the hypothesis that AA is associated with relative insensitivity to VIP stimulation due to reduced VPACs expression, irrespective of whether this is primary (constitutive) or secondary (inflammation-induced) phenomenon, this will render VPAC-mediated signalling an even more promising therapeutic target for future AA management. Indeed, decreased VPAC1/2 expression was previously described also in other autoimmune diseases, ${ }^{36}$ suggesting that defects in VIP receptor/signalling system may be a predisposing factor for the development of autoimmune conditions. This renders it even more pertinent to dissect in future studies whether the decreased VPACs expression in lesional AA HFs detected here plays a functionally important role in the primary pathobiology of AA or reflects only a secondary event triggered by perifollicular inflammation. However, the fact that INF $\gamma$ treatment alone did not cause reduction of VPACs expression in the HF proximal ORS, suggests that the down-regulation of VPAC1/2 in AA HFs is most probably a secondary phenomenon associated with the development of AA.

In any case, our pilot study strongly supports that VIP and more stable VPACs agonists ${ }^{10,12}$ deserve to be fully explored as adjunct candidate therapeutics in the future management of AA. Although VIP and its analogues may not be used to cure an already fully developed-AA (at least alone), they can be used as protectors of AA development. Specifically, VIP and its analogues may reduce the progression and spreading of alopecic foci in AA and might assist in the HF's attempt to reconstruct its collapsed IP, which is felt to be a fundamental prerequisite of spontaneous AA remission. ${ }^{1,2}$ Despite the fact that we have showed a relative down-regulation of VPAC1/2 in AA patients, the use of VIP as a treatment is still relevant because AA hair bulbs have still the ability to respond to exogenous VIP. Moreover, it was recently described that VPAC1 expression is up-regulated by VIP itself. ${ }^{49}$ Therefore, it is expected that

This article is protected by copyright. All rights reserved. 
treatment with VIP analogues would have the similar positive feedback effect. However, a combination therapy, which aims first to up-regulate the expression of VPAC1/2 on the cell surface ${ }^{50,51}$ and then subsequently activates these receptors with appropriate agonists may be the most promising therapeutic approach.

In summary, our study identifies VIP as a promising candidate "HF-IP guardian" neuropeptide that deserves systematic clinical exploration in future AA management, namely for preventing the progression of established AA lesions.

\section{Acknowledgements}

We would like to thank Mrs. Kerasia Plachouri for the recruitment of AA patients, Dr. Erika Lisztes for performing the qRT-PCR analysis and Mrs. L. Jadkauskaite and Mrs. F. Zilio for helpful suggestions. Dr. M. Alam is gratefully acknowledged for his help with text editing.

\section{References}

1 McElwee KJ, Gilhar A, Tobin DJ, et al. What causes alopecia areata? Exp Dermatol 2013; 22:609-26.

2 Gilhar A, Etzioni A, Paus R. Alopecia areata. N Engl J Med 2012; 366:1515-25.

3 Paus R, Nickoloff BJ, Ito T. A 'hairy' privilege. Trends Immunol 2005; 26:32-40.

4 Ito T, Ito N, Bettermann A, et al. Collapse and restoration of MHC class-I-dependent immune privilege: exploiting the human hair follicle as a model. Am J Pathol 2004; 164:623-34.

5 Christoph T, Müller-Röver S, Audring $\mathrm{H}$, et al. The human hair follicle immune system: cellular composition and immune privilege. Br J Dermatol 2000; 142:862-73.

6 Meyer KC, Bodó E, Brzoska T, et al. Immunomodulatory effects of the alpha-melanocyte-stimulating hormone-related tripeptide K(D)PT on human scalp hair follicles under proinflammatory conditions. Br J Dermatol 2009; 161:1400-3.

This article is protected by copyright. All rights reserved. 
7 Kinori M, Bertolini M, Funk W, et al. Calcitonin gene-related peptide (CGRP) may award relative protection from interferon- $\psi$-induced collapse of human hair follicle immune privilege. Exp Dermatol 2012; 21:223-6.

8 Siebenhaar F, Sharov AA, Peters EMJ, et al. Substance $P$ as an immunomodulatory neuropeptide in a mouse model for autoimmune hair loss (alopecia areata). J Invest Dermatol 2007; 127:1489-97.

9 Peters EMJ, Liotiri S, Bodó E, et al. Probing the effects of stress mediators on the human hair follicle: substance P holds central position. Am J Pathol 2007; 171:1872-86.

10 Chandrasekharan B, Nezami BG, Srinivasan S. Emerging neuropeptide targets in inflammation: NPY and VIP. Am J Physiol Gastrointest Liver Physiol 2013; 304:G949-57.

11 Lotti T, D'Erme AM, Hercogová J. The role of neuropeptides in the control of regional immunity. Clin Dermatol 2014; 32:633-45.

12 Mathioudakis A, Chatzimavridou-Grigoriadou V, Evangelopoulou E, Mathioudakis G. Vasoactive intestinal Peptide inhaled agonists: potential role in respiratory therapeutics. Hippokratia 2013; $17: 12-6$.

13 Gonzalez-Rey E, Chorny A, Delgado M. Regulation of immune tolerance by anti-inflammatory neuropeptides. Nat Rev Immunol 2007; 7:52-63.

14 Kinori M, Kloepper JE, Paus R. Can the hair follicle become a model for studying selected aspects of human ocular immune privilege? Invest Ophthalmol Vis Sci 2011; 52:4447-58.

15 Taylor AW, Streilein JW, Cousins SW. Immunoreactive vasoactive intestinal peptide contributes to the immunosuppressive activity of normal aqueous humor. J Immunol Baltim Md 1950 1994; 153:1080-6.

16 Jiang X, McClellan SA, Barrett RP, et al. The role of VIP in cornea. Invest Ophthalmol Vis Sci 2012; 53:7560-6.

17 Koh S-W, Rutzen A, Coll T, et al. VIP immunoreactivity in human aqueous humor. Curr Eye Res 2005; 30:189-94.

18 Taylor AW. Neuroimmunomodulation and immune privilege: the role of neuropeptides in ocular immunosuppression. Neuroimmunomodulation 2002; 10:189-98.

19 Cheng-Chew SB, Leung PY. Localisation of VIP-and CGRP-like substances in the skin and sinus hair follicles of various mammalian species. Histochem Cell Biol 1996; 105:443-52.

20 Hartschuh W, Reinecke M, Weihe E, Yanaihara N. VIP-immunoreactivity in the skin of various mammals: immunohistochemical, radioimmunological and experimental evidence for a dual localization in cutaneous nerves and merkel cells. Peptides 1984; 5:239-45.

This article is protected by copyright. All rights reserved. 
21 Hartschuh W, Weihe E, Yanaihara N, Reinecke M. Immunohistochemical localization of vasoactive intestinal polypeptide (VIP) in Merkel cells of various mammals: evidence for a neuromodulator function of the Merkel cell. J Invest Dermatol 1983; 81:361-4.

22 Schulze E, Witt M, Fink T, et al. Immunohistochemical detection of human skin nerve fibers. Acta Histochem 1997; 99:301-9.

23 Lundeberg L, Nordlind K. Vasoactive intestinal polypeptide in allergic contact dermatitis: an immunohistochemical and radioimmunoassay study. Arch Dermatol Res 1999; 291:201-6.

24 Nolano M, Provitera V, Caporaso G, et al. Cutaneous innervation of the human face as assessed by skin biopsy. J Anat 2013; 222:161-9.

25 Kloepper JE, Sugawara K, Al-Nuaimi Y, et al. Methods in hair research: how to objectively distinguish between anagen and catagen in human hair follicle organ culture. Exp Dermatol 2010; 19:305-12.

26 Lebonvallet N, Boulais N, Le Gall C, et al. Effects of the re-innervation of organotypic skin explants on the epidermis. Exp Dermatol 2012; 21:156-8.

27 Bertolini M, Zilio F, Rossi A, et al. Abnormal interactions between perifollicular mast cells and CD8+ Tcells may contribute to the pathogenesis of alopecia areata. PloS One 2014; 9:e94260.

28 Schulz S, Röcken C, Mawrin C, et al. Immunocytochemical identification of VPAC1, VPAC2, and PAC1 receptors in normal and neoplastic human tissues with subtype-specific antibodies. Clin Cancer Res Off J Am Assoc Cancer Res 2004; 10:8235-42.

29 Tilling T, Wladykowski E, Failla AV, et al. Immunohistochemical analyses point to epidermal origin of human Merkel cells. Histochem Cell Biol 2014; 141:407-21.

30 Taira K, Narisawa Y, Nakafusa J, et al. Spatial relationship between Merkel cells and Langerhans cells in human hair follicles. J Dermatol Sci 2002; 30:195-204.

31 Boulais N, Pereira U, Lebonvallet N, et al. Merkel cells as putative regulatory cells in skin disorders: an in vitro study. PloS One 2009; 4:e6528.

32 Maksimovic S, Baba Y, Lumpkin EA. Neurotransmitters and synaptic components in the Merkel cellneurite complex, a gentle-touch receptor. Ann N Y Acad Sci 2013; 1279:13-21.

33 Fischer TC, Hartmann P, Löser C, et al. Abundant expression of vasoactive intestinal polypeptide receptor VPAC2 mRNA in human skin. J Invest Dermatol 2001; 117:754-6.

34 Fischer TC, Dinh QT, Peiser C, et al. Simultaneous detection of receptor mRNA and ligand protein in human skin tissues. J Cutan Pathol 2002; 29:65-71.

35 Wollina U, Paus R, Feldrappe S. Sequential expression of glutathione-S-transferase isoenzymes during hair growth phases in mice and their relationship to caldesmon, phosphotyrosinase and VIP receptor protein. Histol Histopathol 1995; 10:39-45.

This article is protected by copyright. All rights reserved. 
36 Delgado M, Ganea D. Vasoactive intestinal peptide: a neuropeptide with pleiotropic immune functions. Amino Acids 2013; 45:25-39.

37 Kulka M, Sheen $\mathrm{CH}$, Tancowny BP, et al. Neuropeptides activate human mast cell degranulation and chemokine production. Immunology 2008; 123:398-410.

38 Seeliger S, Buddenkotte J, Schmidt-Choudhury A, et al. Pituitary adenylate cyclase activating polypeptide: an important vascular regulator in human skin in vivo. Am J Pathol 2010; 177:2563-75.

39 Edamura M, Murakami G, Meng H, et al. Functional deficiency of MHC class I enhances LTP and abolishes LTD in the nucleus accumbens of mice. PloS One 2014; 9:e107099.

40 Chiou S-J, Chen C-H. Decipher $\beta 2$-microglobulin: gain- or loss-of-function (a mini-review). Med Sci Monit Basic Res 2013; 19:271-3.

41 York IA, Rock KL. Antigen processing and presentation by the class I major histocompatibility complex. Annu Rev Immunol 1996; 14:369-96.

42 Castellana D, Paus R, Perez-Moreno M. Macrophages contribute to the cyclic activation of adult hair follicle stem cells. PLoS Biol 2014; 12:e1002002.

43 Kambayashi T, Laufer TM. Atypical MHC class II-expressing antigen-presenting cells: can anything replace a dendritic cell? Nat Rev Immunol 2014; 14:719-30.

$44 \mathrm{Fu} \mathrm{H}$, Kishore M, Gittens B, et al. Self-recognition of the endothelium enables regulatory T-cell trafficking and defines the kinetics of immune regulation. Nat Commun 2014; 5:3436.

45 Card CM, Yu SS, Swartz MA. Emerging roles of lymphatic endothelium in regulating adaptive immunity. J Clin Invest 2014; 124:943-52.

46 Streilein JW, Okamoto S, Sano Y, Taylor AW. Neural control of ocular immune privilege. Ann N Y Acad Sci 2000; 917:297-306.

47 Toyoda M, Makino T, Kagoura M, Morohashi M. Expression of neuropeptide-degrading enzymes in alopecia areata: an immunohistochemical study. Br J Dermatol 2001; 144:46-54.

48 Wollman Y, Blumberg S, Spungin A, et al. The increased proliferation of cultured neuroblastoma cells treated with vasoactive intestinal peptide is enhanced by simultaneous inhibition of neutral endopeptidase. Regul Pept 2002; 108:175-7.

49 Kakurai M, Fujita N, Murata S, et al. Vasoactive intestinal peptide regulates its receptor expression and functions of human keratinocytes via type I vasoactive intestinal peptide receptors. J Invest Dermatol 2001; 116:743-9.

50 Chignard N, Mergey M, Barbu V, et al. VPAC1 expression is regulated by FXR agonists in the human gallbladder epithelium. Hepatol Baltim Md 2005; 42:549-57.

This article is protected by copyright. All rights reserved. 
51 Waschek JA, Muller JM, Duan DS, Sadée W. Retinoic acid enhances VIP receptor expression and responsiveness in human neuroblastoma cell, SH-SY5Y. FEBS Lett 1989; 250:611-4.

52 Hordinsky M, Ericson M, Snow D, et al. Peribulbar innervation and substance P expression following nonpermanent injury to the human scalp hair follicle. J Investig Dermatol Symp Proc Soc Investig Dermatol Inc Eur Soc Dermatol Res 1999; 4:316-9.

\section{Figure legends}

Fig. 1 VIP and VIP receptors (VPAC1, VPAC2) are transcribed in human HFs.

qRT-PCR analysis of dispase treated microdissected anagen VI HFs revealed that VIP, VPAC1 and VPAC2 transcripts are detected in the HF epithelium, with substantial interindividual expression differences. Of note, VIP transcript was not detected in one well out of three wells analysed (measurements) in two individuals, while VPAC2 transcript was not detected in one well out of three wells analysed (measurements) in one individual. $\mathrm{N}=18 \mathrm{HFs} /$ individual, 3 repeated measurements were performed for each individual, 3 individuals analysed for each transcript analysed; mean \pm SEM.

Fig. 2 VIP protein is expressed in perifollicular nerve fibers.

Representative images of VIP immufluorescence in human skin (a-c). VIP ${ }^{+}$nerve fibers are localized around healthy control hair bulb $(a, b)$. As internal positive control, nerve fibers around sweat glands revealed VIP IR (c) as previously shown. ${ }^{22,28,34}$ Representative images showing nerve fibers (detected by Pgp9.5) (d) positive for VIP (e) around sweat gland and HF in human healthy skin, confirming that the $\mathrm{VIP}^{+} \mathrm{IR}$ in panels a and $\mathrm{b}$ represents $\mathrm{VIP}^{+}$nerve fibers (f). Arrows indicate Pgp9.5 $5^{+} \mathrm{VIP}^{+}$nerve fibers, arrowheads indicate Pgp9. $5^{+} \mathrm{VIP}^{-}$nerve fibers. Original magnification: 200x. Dermal papilla (DP), hair matrix (HM), sebaceous gland (SBG), sweat gland (SG).

This article is protected by copyright. All rights reserved. 
Fig. 3 VIP receptor (VPAC1, VPAC2) proteins are differentially expressed in human HFs.

Representative picture of the positive control, the gastrointestinal tract tissue, showing neuroendocrine cells positive for $\operatorname{VPAC}^{28}$ (a). As internal positive control, also the epidermis reveals $\operatorname{VPAC} 1 \mathrm{IR}^{23}$ (b). VPAC1 is only slightly expressed by the bulge (c) and lower (d) HF ORS while it is strongly detected in the HF bulb (e). In panel e, a higher magnification image showing VPAC1 ${ }^{+}$cells in the HF CTS (e). Representative image of the positive control, the gastrointestinal tract tissue, showing neuroendocrine cells positive for $\operatorname{VPAC2}^{28}$ (f). As internal positive control, also the epidermis reveals VPAC2 $\mathrm{IR}^{23}(\mathrm{~g})$. VPAC2 is strongly expressed by the bulge basal layer keratinocytes (h) but almost absent in the lower HF ORS (i). Intensive VPAC2 IR is detected also in the bulb of anagen HF (j) and in the secondary hair germ and ORS of a catagen HF (k). Original magnification: 200x. Arrows indicate positive cells in the control tissue and in the HF CTS. Arrector pili muscle (APM), dermal papilla (DP), epidermis (E), hair follicle (HF), hair matrix (HM), connective tissue sheath (CTS), inner root sheath (IRS), outer root sheath (ORS).

Fig. 4 Lesional AA HFs show a reduced expression of VPAC1 and VPAC2, but not of VIP, compared to healthy HFs.

Representative immunohistology images showing that VPAC1 immunoreactivity is down-regulated in a lesional AA hair bulb (b) when compared to a healthy control hair bulb (a). In accordance, VPAC2 is also reduced in a AA lesional hair bulb (e) when compared to a healthy control hair bulb (d). Original magnification: 200x. Quantitative (immuno-)histomorphometry confirmed these observations (c,f). VPAC1 and VPAC2 immunoreactivitiy were evaluated in the proximal ORS, as indicated in the pictures $(a, d)$. Analysis deriving from $16 \mathrm{HFs}$ of 7 healthy donors and $7 \mathrm{HFs}$ of $5 \mathrm{AA}$ patients characterized by acute or subacute disease phase, mean \pm SEM, Student's $t$-test, ${ }^{* *} p<0.01$. Representative immunohistology images showing that nerve fibers (Pgp 9.5 labelled) negative and positive for VIP around anagen hair bulbs in biopsies from healthy controls $(\mathrm{g}, \mathrm{h})$ and from lesional skin from AA patients in acute (i) and chronic (j) stages of the disease. Please note that as reported before ${ }^{52}$, the Pgp 9.5 immunoreactivity in the hair matrix above the dermal papilla are not nerves but positive cells. Original magnification: 100x.

This article is protected by copyright. All rights reserved. 
Arrows indicate VIP ${ }^{+}$nerve fibers. Dermal papilla (DP), hair matrix (HM), inner root sheath (IRS), outer root sheath (ORS), sweat glands (SG).

Fig. 5 VIP prevents, but does not fully restore HF-IP collapse induced by IFN $\gamma$.

Indirect immunofluorescence for MHC class I (a-c) and corresponding quantitative (immuno)histomorphometry (d) in HFs of the "protection assay" design ("PrA"). Quantitative (immunohistomorphometry) of $\beta 2$-microglubulin IR in HFs of the "PrA" design (e). Immunohistochemistry for MHC class II (f-h) and corresponding quantitative (immuno-)histomorphometry (i) in HFs of the "PrA" design. Indirect immunofluorescence for MHC class I (j-m) and corresponding quantitative (immuno)histomorphometry ( $n$ ) in HFs of the "restoration assay" design ("ReA"). Quantitative (immunohistomorphometry) of $\beta 2$-microglubulin IR in HFs of the "ReA" design (o). Immunohistochemistry for MHC class II (p-r) and corresponding quantitative (immuno-)histomorphometry (s) in HFs of the "ReA" design. Original magnification: 200x. MHC class I and $\beta 2$-microglubulin IR were evaluated in the HM, proximal ORS and CTS using Image $\mathrm{J}$ while MHC class $\mathrm{II}^{+}$cells were counted in the HF bulb CTS. Analysis deriving from $\mathrm{N}=12-30 \mathrm{HFs}$ from 3 different patients, mean $\pm \mathrm{SEM}$, Student's $t$-test, ${ }^{* * *} \mathrm{p}<0.001,{ }^{* *} \mathrm{p}<0.01$, ${ }^{*} \mathrm{p}<0.05$. Dermal papilla (DP), hair matrix (HM), connective tissue sheath (CTS), outer root sheath (ORS).

\section{mRNA expression of VIP, VPAC1 and VPAC2}

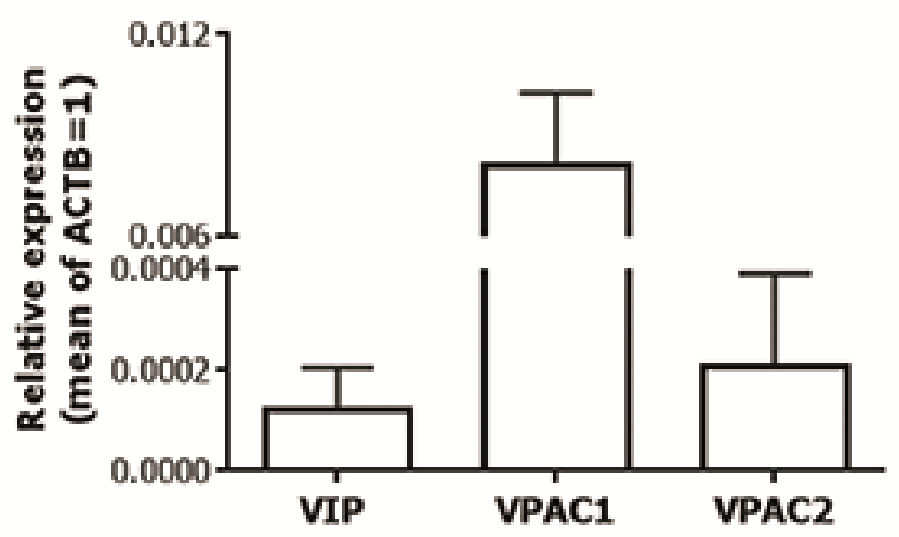

This article is protected by copyright. All rights reserved. 


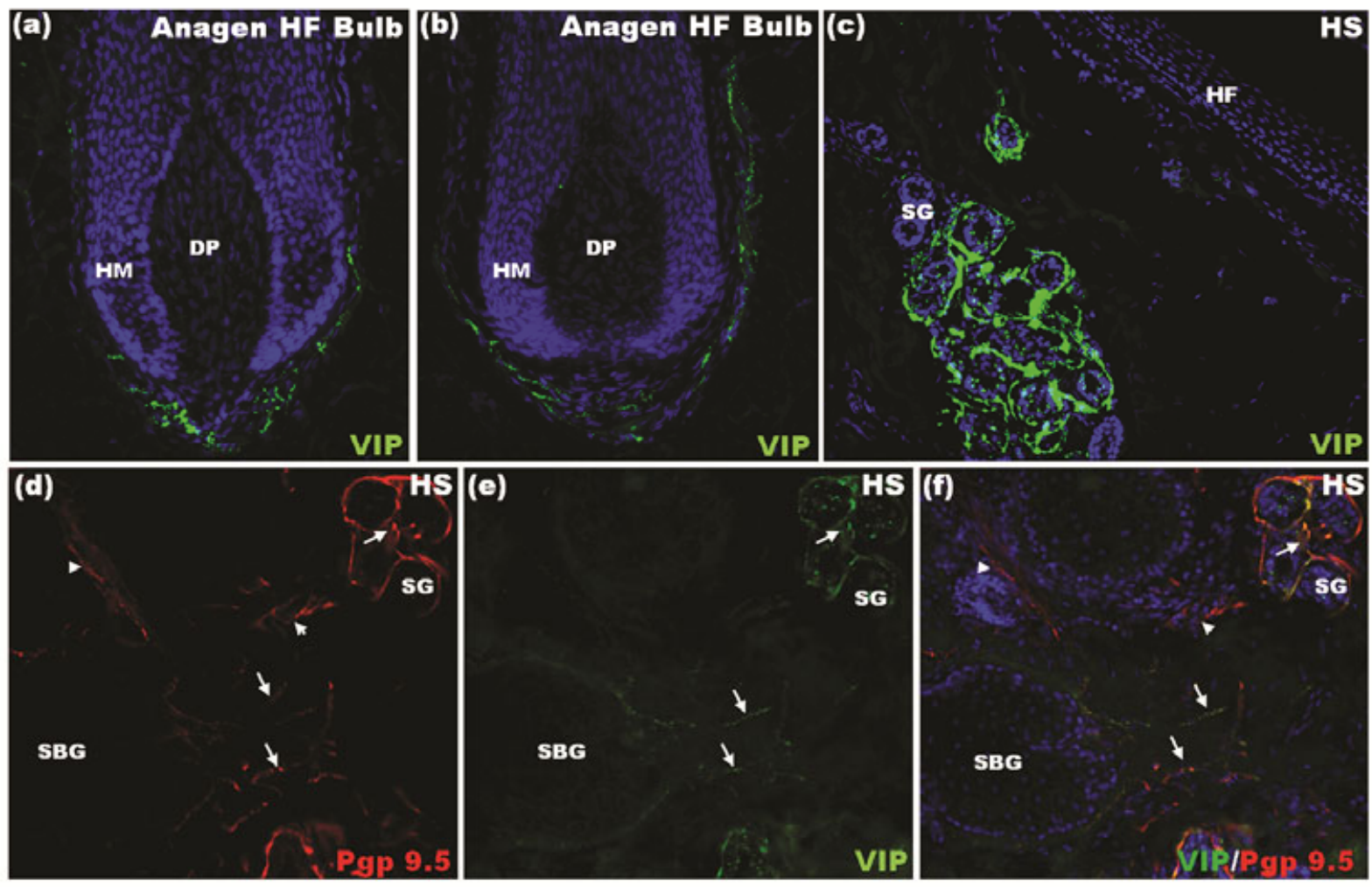

This article is protected by copyright. All rights reserved. 


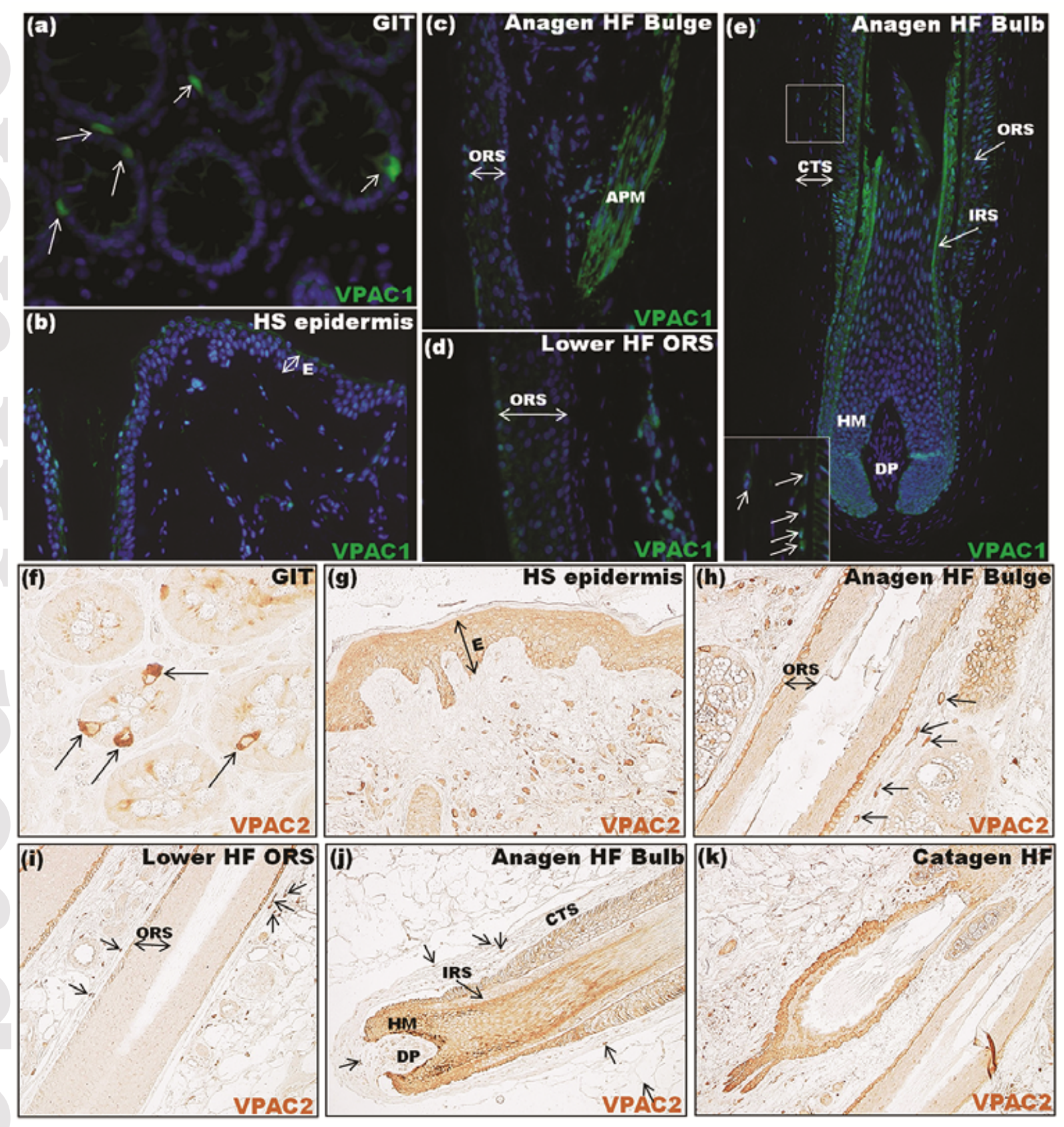

This article is protected by copyright. All rights reserved. 


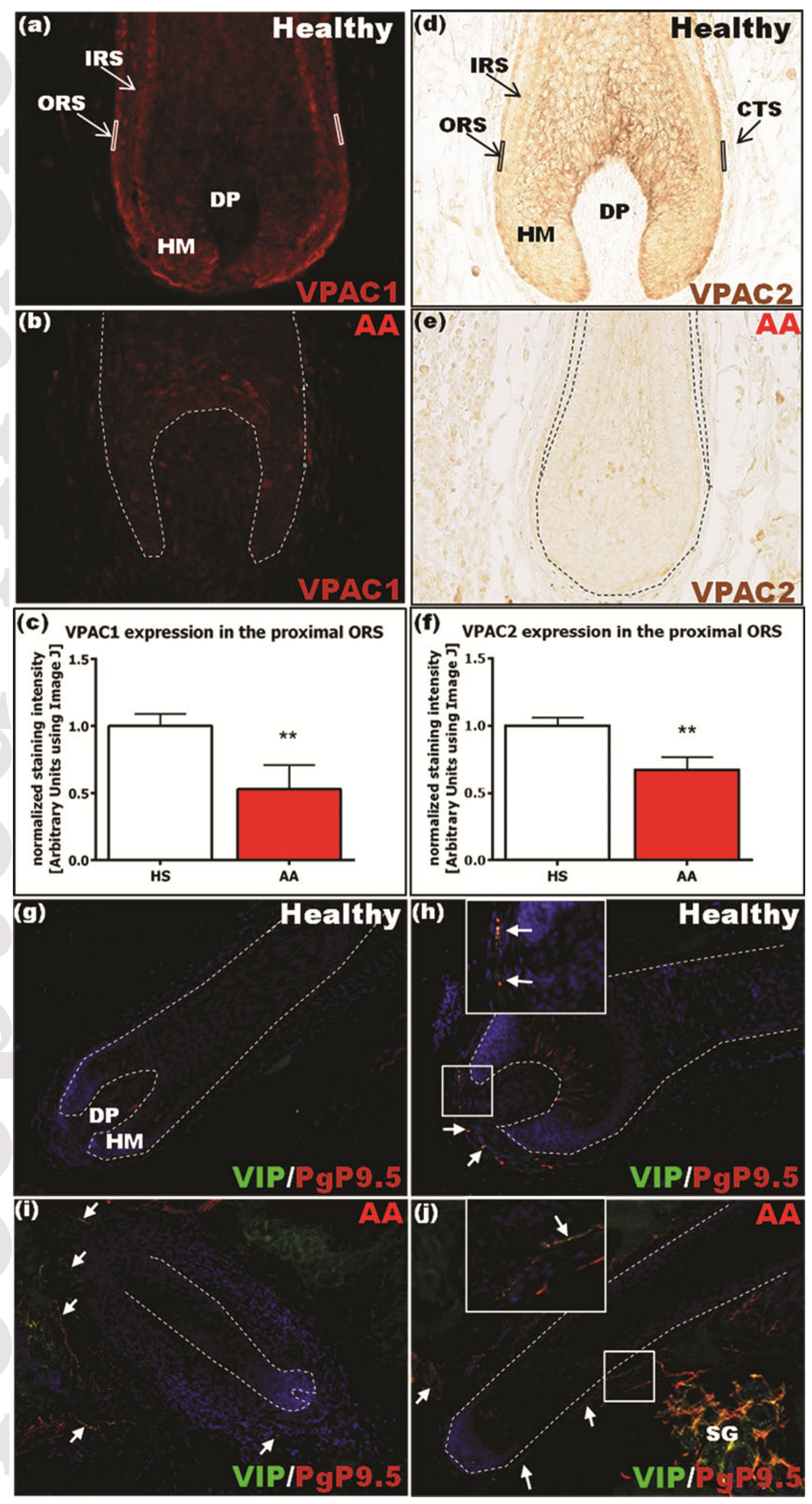

This article is protected by copyright. All rights reserved. 


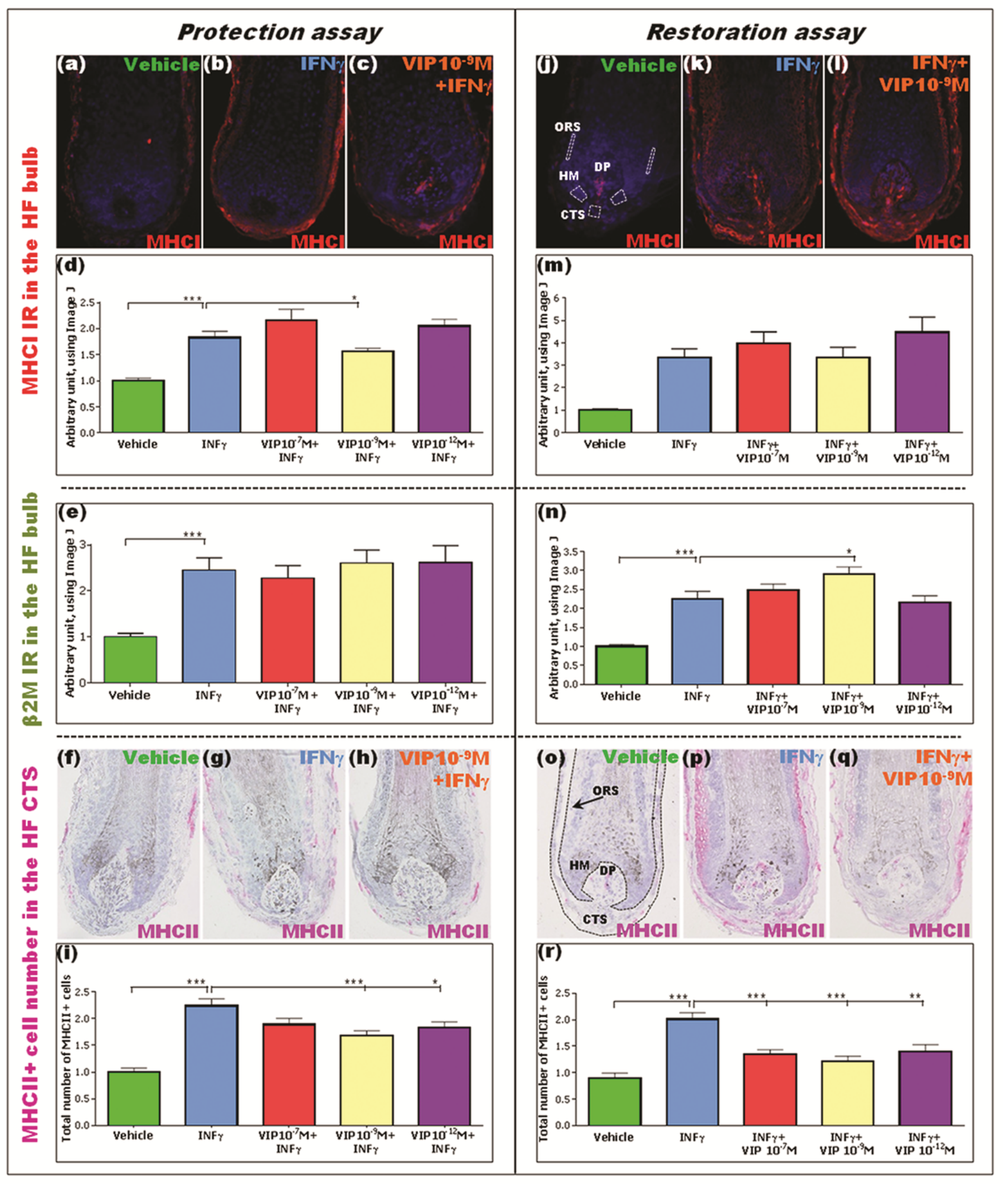

This article is protected by copyright. All rights reserved. 